\title{
EL PALAFITO, LA CASA PRIMIGENIA
}

\author{
(THE PALAFITTE, THE PRIMITIVE HOUSING)
}

Andrés García, Arquitecto. Profesor de la Facultad de Arquitectura - Universidad del Zulia. MARACAIBO. VENEZUELA

\section{RESUMEN}

El trabajo se centra en el estudio de la vivienda de los indios paraujanos al norte del Lago de Maracaibo (Venezuela). Esta vivienda es de tipo palafitico, actualmente amenazada con la desaparición como vivienda, para ser un elemento turistico, que los lleva a ser imágenes folklóricas de un pintoresco subdesarrollo.

Se propone al final del articulo un proyecto de preservación, para evitar la marginalidad y posible desaparición de estos palafitos.

\section{SUMMARY}

This study focuses on the housing of the Paraujano Indians, north of the Maracaibo lake (Venezuela). This housing is of palafitte style and is being threatened to convert into a tourist element, a folkloric image of underdevelopment. At the end of the article, a project for preservation of palafittes is proposed to prevent their possible disappearence.

\section{"Todo tiene ese espacio y el sitio prometido menos el hombre}

que es a quien prometen"**

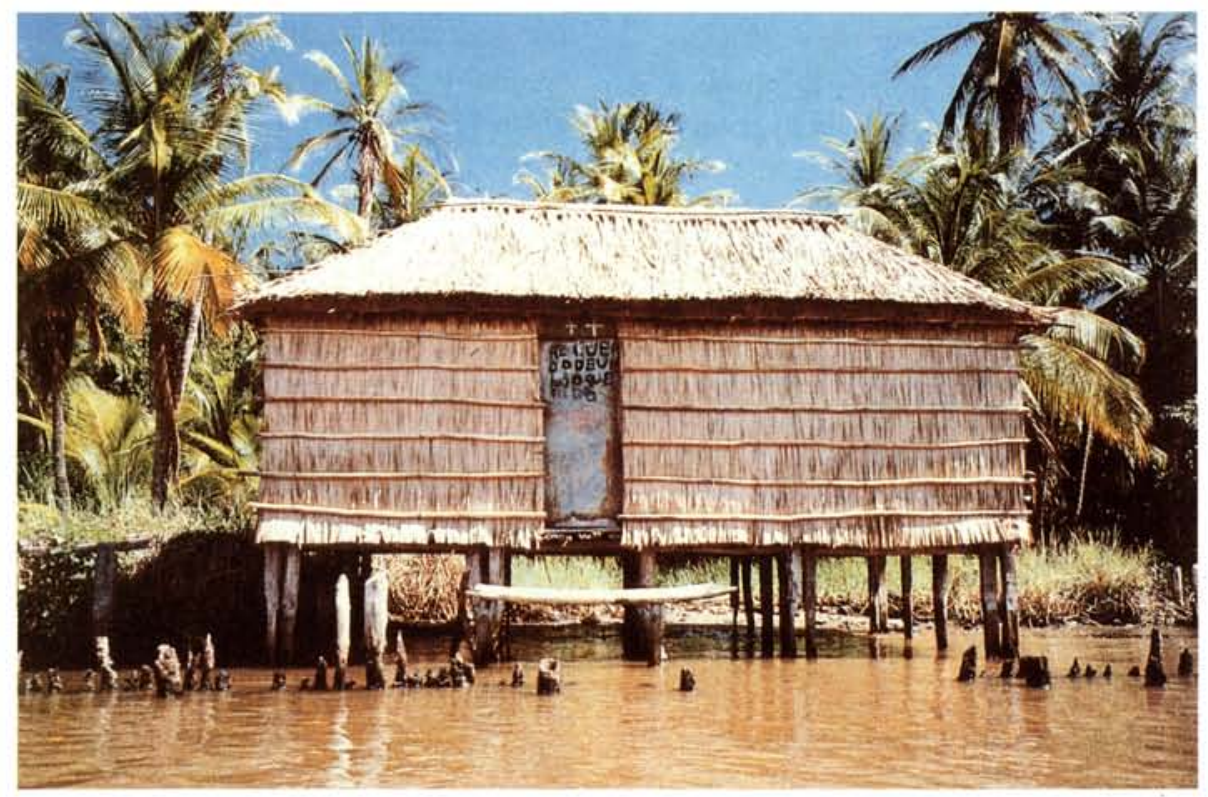




\section{LA CASA. EL HÁBITAT PRIVADO}

"La Ciudad según sentencia de los Filósofos es como una casa grande, y viceversa, la casa es una pequeña ciudad,....'(1)

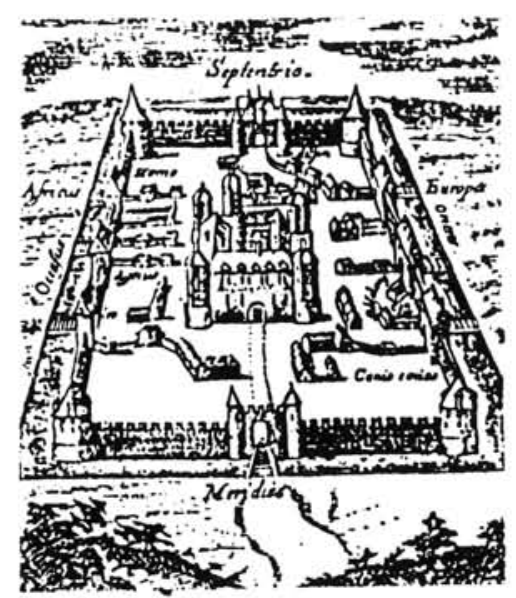

La ciudad simbólica como centro del mundo (de Jung)

Hablar de la casa, es penetrar en los predios de la intimidad, en el escenario doméstico, en ese mundo particular, donde desaparece el anónimo andar para asi asumir en el refugio la búsqueda siempre dialéctica del sendero deseado.

Es el claustro cotidiano donde se radicaliza el modo de vida, el gusto, el uso, el deseo, la memoria; alli se representan en mil formas... tanto nuestras posibilidades como nuestras ambiciones; alli es factible penetrar en las recónditas matrices de la individualidad, alli el sincretismo hombre-familia.

La casa es el lugar primigenio, donde el hombre se identifica con el lenguaje del espacio que lo cobija. Un lenguaje que debe entenderse no como el simple medio que delimita su ambiente, sino como una totalidad que lo representa. Por ende no es sólo forma, sino también contenido; no es sólo fenómeno, sino también esencia; no es sólo significante, sino también significado. Es un lenguaje que internalizado pretende trascender la propia peculiaridad morfológica para proyectarse como paradigma en otros medios, y así competir o diluirse con otras propuestas.

La casa es un lenguaje concreto del ser que desea edificar su impronta perenne. Es el hombre construyendo su historia.

Varias dimensiones acotan las formas de la casa. Por un lado las delimitaciones de su estructura constructiva, sus recintos, sus objetos; por el otro, los parámetros de la rutinaria reflexión que analiza las constantes incompatibilidades entre apetencias y circunstancias, entre posibilidades y restricciones. Alli las pre- guntas sobre el existir, alli las respuestas del ser en su cotidianidad.

La casa es el punto donde fugan nuestras perspectivas. Es hoy que avisora el mañana. Es universo y es singularidad, es centro y es periferia. Es el aposento en que conviven conciencia y alienación... alli el ser que pretende el devenir o la soledad de aquel que perdió el futuro.

La casa... "no es sólo un objeto de uso o una edilicia para el consumo, sino una birrelación dinámica de es. pacio y hombre a través del tiempo. Definirla como una materia obrada producto del hombre y para el hombre, sería sólo describir la superficialidad de su estructura sincrónica, descuidando su proceso y génesis incluidos en el diacronismo esencial de su trama.

El diálogo del hombre con su caparazón material es diario, se produce a cada intante y conciente o inconscientemente nos afecta en todo momento. Por eso la arqui. tectura como materialidad envolvente no es una pre. sencia fortuita, sino que siempre invade nuestras vidas, de alli que la asociación de espacio, materia, hombre, tiempo, sea una totalidad indisoluble".(2)

Si bien para algunos filósofos o legos, la casa es el lugar destinado a "morar"; considero que ello restringe el sentido de la casa. Pues "morar" etimológicamente denota detenerse, quedarse o permanecer, y la casa no es sólo guarida, sino en especial vida, existencia; es el lugar donde el ser se mueve y adquiere su primaria conciencia dialéctica, que deslindada de todo idealismo, procura el ambiente por el que cotidianamente lucha. La casa no es sólo un construir para residir, permanecer o morar, sino un anfitrión constante de un sin fín de proyectos que no gustan del detenerse, quedarse o permanecer.

La casa es la expresión concreta del ser en situación. Situación que implica represiones, a la vez que explicita el afán superador, es la génesis de esa lucha por aquella utopía que está al alcance de la mano.

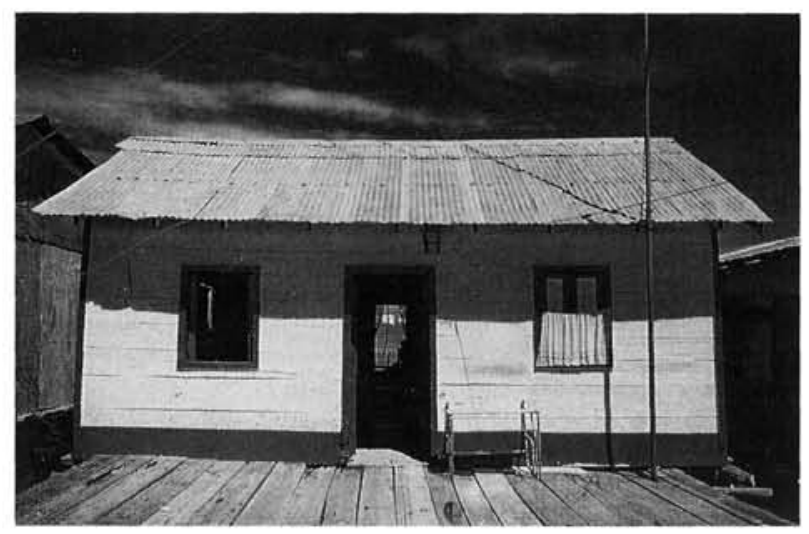

http://informesdelaconstruccion.revistas.csic.es 
Por lo expuesto, tampoco es posible concebir a la casa sólo como un cúmulo de recuerdos o el lugar de los sueños... el espacio onírico; sino en especial como el topos donde se afirma el ser y como tal en donde nace la propuesta de superación del propio espacio que habita. Porque la casa si bien puede albergar a morfeo, es también el "morfos" del confort. No admitir esta conjunción puede sin dudas llevarnos a terrenos de una concepción sublimante que nos precipite a la falacia de sobrevaluar lo pintoresco, lo anecdótico, lo vernáculo o la simple imagen folklórica; en desmedro de encontrar el camino hacia una poética de lo concreto.

Antonio Fernández Alba, nos alerta de la "Deformación de los enfoques históricos en torno de la denominada arquitectura popular", al exponer lo siguiente:

"Sobre el tema tan genérico como impreciso de la de. nominada arquitectura popular, se ha vertido un cúmulo tal de adjetivaciones que hoy su estudio se encuentra, al menos desde la perspectiva arquitectónica, desvinculado de sus raíces más genuinas. Ha sido campo de especulación para un romanticismo formal de marca. do talante esteticista que veía en estos espacios unas formas idóneas para contrarrestar el modelo racionalista, que se presentaba desvinculado de toda raiz his. tórica. Fue en tiempos no muy lejanos una tentación para muchos arquitectos, un código lleno de alegorias fotogénicas, que dada su gran riqueza plástica supliría la capacidad compositiva que dejó como herencia el Movimiento Moderno. Tampoco estuvieron exentos estos productos populares de la indagación y posterior reducción a un marco teórico, en el cual poder es. pecular soluciones para un hábitat universal, desde el lema bien acuñado: "la arquitectura sin arquitectos", hasta los modelos de C. Alexander existe una vasta literatura en torno de una realidad espacial muy concre. ta. Significados sociales, significados culturales, significado de la materialidad, cambio en el significado del medio, han sido apartados que desde distintos planos de rigor metodológico incidieron sobre estos objetos arquitectónicos perdidos en la memoria de los márgenes, adulterados en sus contenidos más primarios, explotados dentro de la industria cultural de la imagen, supervalorados por una actitud nostálgica, tan característica como sospechosa dentro de la sensibilidad moderna y que ha producido una expoliación de sus valores culturales, y una usurpación de su sabiduría.

La arquitectura de los arquitectos se utiliza como modelo privativo de una determinada clase, la arquitectu. ra popular como un subproducto que la imaginación del pueblo, lleno de recursos y artificios elementales, agudiza ante la necesidad y dentro de la penuria de unos medios materiales cuyo resultado final es la formalización del estereotipo, Modelo versus Estereotipo ha sido y sigue siendo el modo decepcionante con el que se enfrentan muchos de los enfoques históricos que se han realizado o se inician en la actualidad en torno de unos espacios concebidos desde unas bases naturales de subsistencia que se presentan como homogéneas. Será preciso, aunque sea desde estas plataformas reducidas y casuales, indicar la necesidad de acabar con los equívocos de lo popular al menos des. de los presupuestos teóricos del ensayo arquitectóni$\mathrm{co}$, para indagar un entendimiento, algo diferente a los enunciados retóricos que en la actualidad persisten".(3)

Como es fácil inferir de lo antedicho, es dificil el penetrar en una arquitectura de tradición popular, en un producto de una específica situación histórica que simboliza el espacio primigenio del lugar. Difícil, pues requiere una profunda valoración de lo legado, para asi luego penetrar en la posibilidad de dirimir entre aquello que es loable que perdure, de aquello que es necesario mutar.

Hoy es dable señalar que las Historias de la Arquitectura, en mucho olvidaron de la casa, quizás porque prodigaron su atención al monumento, a la edilicia de las instituciones, a los recintos del poder; descuidando así la vital célula ciudadana: el gran espacio de la cotidianidad. Por ende al marginarse de las historias los sucesos de la marginalidad, es sumamente difícil penetrar con cierta objetividad científica en la vida pasada de nuestros ancestros.

Hoy, como es notorio, el objetivo es superar el olvido. Penetrar en los recintos de la individualidad. Recordar el hábitat de primitivos artífices. Recorrer sin prejuicios las remotas imágenes del hacer de antaño y renovar aquella declaración de derechos, como lo son el vivir en un ambiente sano y poseer un espacio digno.

"La arquitectura contemporánea es la arquitectura de la vivienda: en este hecho fundamental reside la diferencia sustancial con la arquitectura de todas las épocas que la preceden...'(4)

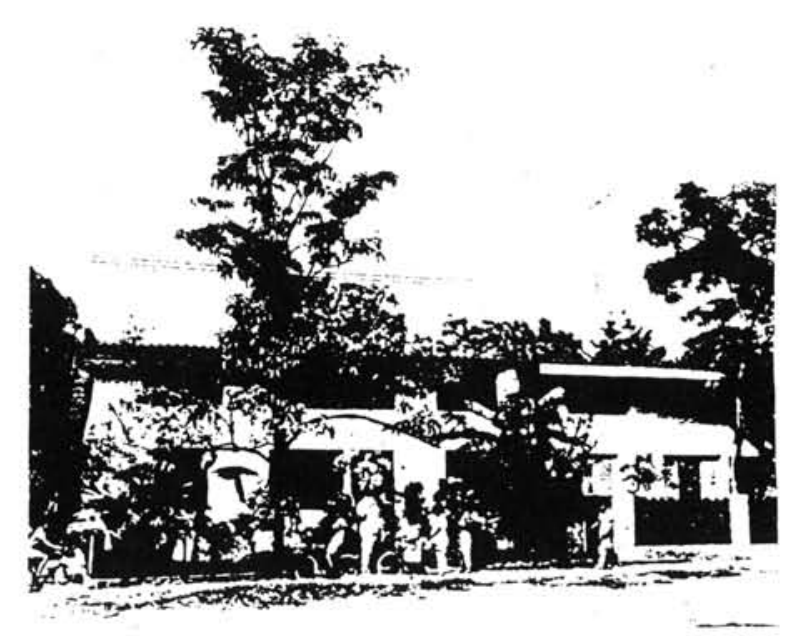

Urbanización Gral. R. Urdaneta, Maracaibo, Arq. C.R. Villanueva. http://informesdelaconstruccion.revistas.csic.es 


\section{EL HOGAR}

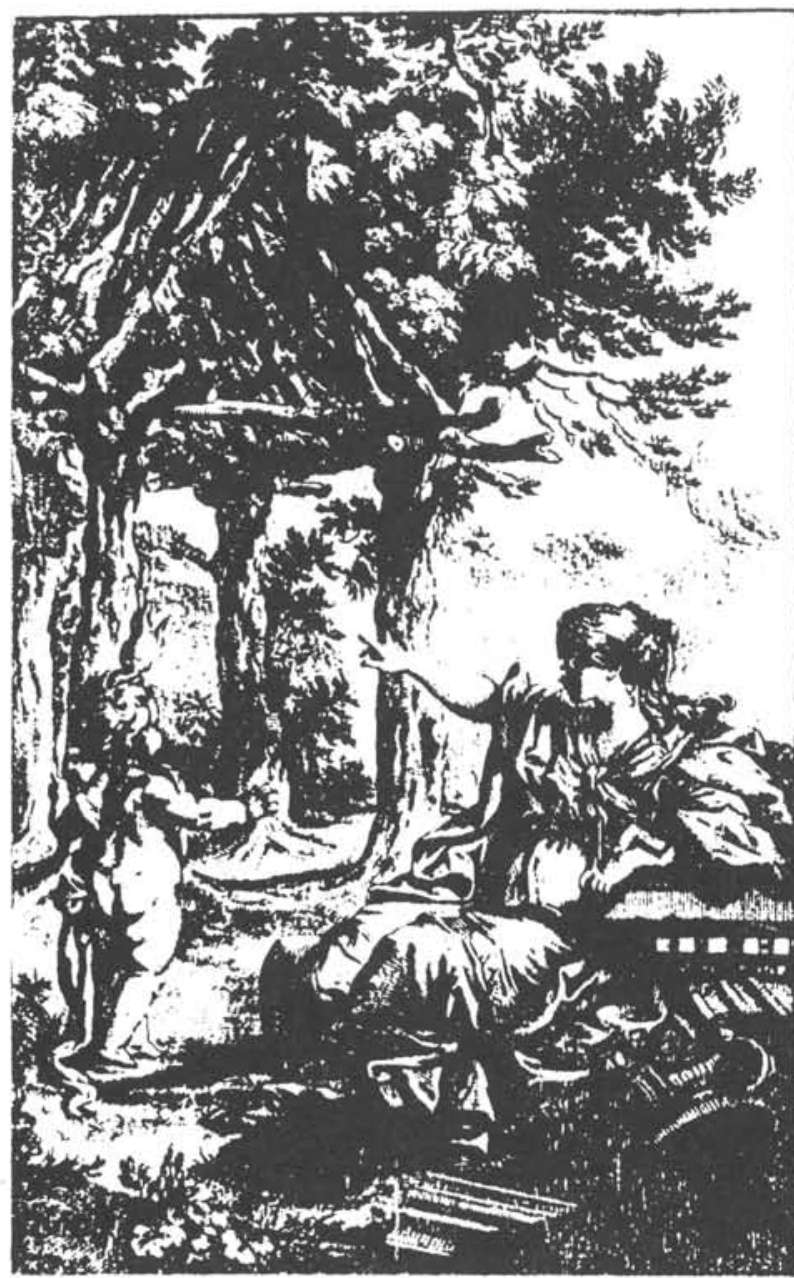

"La Cabane Rustique".

Grabado de Ch. Eisen, aparecido en ESSAI SUR L'ARCHITECTURE obra de Marc-Antoine Laugier. 1753

"Dicese que los hombres, que al principio habitaban en montes y cabernas como fieras, se juntaron para fabricar casas y formar Poblaciones; y que esto sucedió con motivo de un incendio causado por el viento en una selva, á cuya novedad y efectos prodigiosos acudia to. da la gente: $y$ asi habiendose encontrado juntos muchos hombres en un mismo lugar, ayudandose unos a otros, hallaron medio de guarecerse mejor que baxo los arboles ó las cabernas. De aqui nace pretender sea la Arquitectura el principio y origen de las demas Artes: pues advirtiendo los hombres lo bien que les habia salido la de hacer Casas, cuya invencion debieron á la necesidad, formaron el designio, y se animaron á buscar otras y aplicarse á ellas.

Al modo que los arboles y los peñascos, con que la naturaleza da por si misma abrigo a los animales, sirvieron de norma para edificar las primeras Habitaciones, que eran sólo de céspedes y troncos quitadas las ramas; asi también estas mismas Habitaciones sirvieron de ejemplo para llegar a obras más perfectas; porque pasando de la imitación de lo natural a la de lo artifi. cial, inventaron todos los ornatos de los más primoro. sos Edificios..."'(5)

Hablar del "hogar" es recordar el primigenio lugar del fuego, el "locus foci", el topos de la llama que anima al sedentario, la luz que despeja las dudas de la oscuridad, el amparo térmico, la cocción de alimentos, el solar recóndito donde despierta la cultura.

En la segunda mitad del siglo XVII, Juan de Caramuel (1606-1682), el primer tratadista en hacer referencia a hogares primitivos en América, ilustra con estos antiguos recintos el surgir de la arquitectura. Asi Caramuel al hablar: "De las casas Antiguas", expresa lo siguiente en relación a su décima lámina del tratado:

"Representa diferentes habitaciones, que tenian los Indios en América, cuando vinieron alla los Españoles.

Hay hoy en Europa, en aldeas y lugares pobres, tugurios y habitaciones semejantes: $y$ parece, que todas en España havran sido asi en los siglos antiguos, porque las, que el Latino llama Domos, llama el Español Casas".(6)

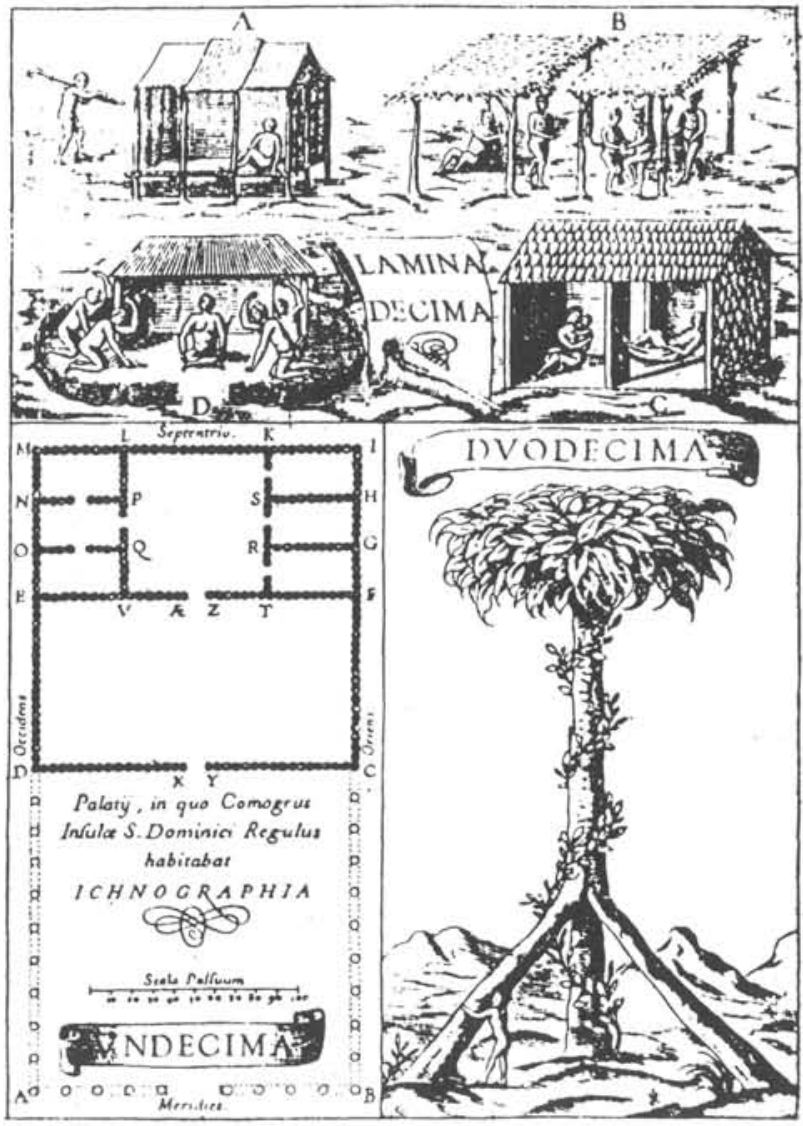

Láminas X, XI y XII del Tratado de Juan Caramuel de L. (6) http://informesdelaconstruccion.revistas.csic.es 
Como es de suponer por los ejemplos que ilustran el tratado de Caramuel, él sólo tiene noticias de algunas construcciones en las primeras islas colonizadas en el Caribe, y desconcce la obra de las grandes culturas del continente.

\section{LA REGIÓN ZULIANA}

"Catedral de la luz, de agua, de viento...," en estas palabras del poeta I gnacio de la Cruz, quizás la más ajustada descripción del ámbito zuliano. Una intensa luz para el crisol de razas, un agua abundante para bendecir su pródiga naturaleza y un fuerte viento para llevar al olvido las injusticias de que fue $y$ sigue siendo objeto... Y podriamos extender aquella definición de Maracaibo, para asi decir... Zulia: "la tierra del sol amada".

La región se extiende desde las serranias de Perijá hasta unas millas más allá de la ribera oriental del Lago de Maracaibo, y del mar Caribe al pedemonte de las andinas sierras de Mérida. El Lago es sin duda su epicentro, con una extensión superior a los $14.000 \mathrm{~km}^{2}$. Su forma que semeja una gota, posee un eje de simetría norte-sur de unos $155 \mathrm{~km}$ de longitud. Su ancho esteoeste es variable, con un máximo de $100 \mathrm{~km}$ que decrece hasta unos $10 \mathrm{~km}$ en las puertas de un canal natural que lo vincula con el Golfo de Venezuela.

Su clima es constantemente cálido con una media de $30^{\circ}$, su límite sur se caracteriza por una frondosidad tropical que va desvaneciéndose hacia el norte.

La historia nos cuenta que: Alonso de Ojeda, acompañante de Colón en su segundo viaje, organiza a fines del siglo XV su propia expedición con la colaboración de Juan de la Cosa y Américo Vespucio. Asi recorre las costas que van desde el Delta Amacuro a la Península Guajira, penetrando un 24 de agosto de 1499 en aguas del Coquivacoa, voz que identificaba el hoy Lago de Maracaibo. Alli el primer contacto de la conquista con un hábitat lacustre que trae a la memoria de los navegan. tes las imágenes del Veneto, recuerdo que trasciende al bautizarse el lugar con el nombre quizás peyorativo de... "Venezuela".

En 1528 Carlos V cede a los Welser de Augsburgo la empresa conquistadora de la Provincia de Venezuela. Ambrosius de Alfinger oficia de adelantado e incursiona varias veces en el Lago. Crónicas de la época na. rran que para 1531 una de estas expediciones descubre tres asentamientos de la tribu Onoto.

“... estaban despoblados, porque sus habitantes al aproximarse los españoles los dejaron solos. Más a la vuelta del gobernador Dalfinger, los indios le dirigieron fle. chas de que no recibieron daño. Estos pueblos están en el agua, armados sobre puntales de palmas muy fuertes".(7)

En 1569, Alonso de Pacheco establece el germen de la actual Maracaibo, cuya estructura recién se conso. lidan para 1574, cuando Pedro Maldonado la refunda bajo el nombre de Nueva Zamora.

La gesta independentista se inicia en 1811 y culmina con la Batalla del Lago de Maracaibo el 24 de julio de 1823. Bolivar, el "Gran Libertador", presidente para 1819 de la "Gran Colombia" y precursor de la unidad latinoamericana; verá a su postre en 1830 esfumar sus anhelos, al producirse mezquinos enfrentamientos entre sus sucesores, lo que significará el loteo de su digna herencia.

La etapa 1830 a 1935 en la historia venezolana es un siglo de guerras internas y un largo espectro de caudillos en el poder, que adquiere máxima expresión con la figura patriarcal de Juan Vicente Gómez. Luego de su muerte y a partir de la llamada "generación del 28 " se irá gestando en el pais una pública conciencia democrática, la que se consolida plenamente desde los comicios de 1958.

Desde la colonia la región ha padecido una constante marginalidad respecto a los centros de poder, a pesar de sus importantes recursos; como los tradicionales de pesca, madera y frutas, que luego incrementados por una próspera actividad pecuaria y riquísimos yacimientos petroleros y carboniferos, hoy la convierten en la zona de mayor producción y potencial económico del pais.

"Hay un golpe de sal

y viento desflecado en brisa que retoza.

La casa es la piragua en su aparejo

$y$ es un color surgido desde el fruto, un encontrar el hombre su módulo por dentro"*

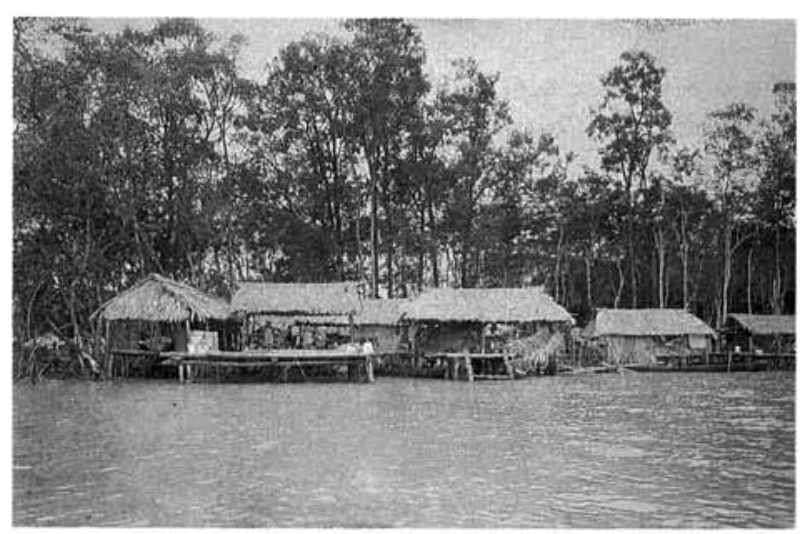

-DE LA CRUZ, Ignacio. Viñetas de Maracaibo. Maracaibo. Editorial del Lago. Ve. nezuela, 1979 .

http://informesdelaconstruccion.revistas.csic.es 


\section{LOS ASENTAMIENTOS PALAFITICOS}
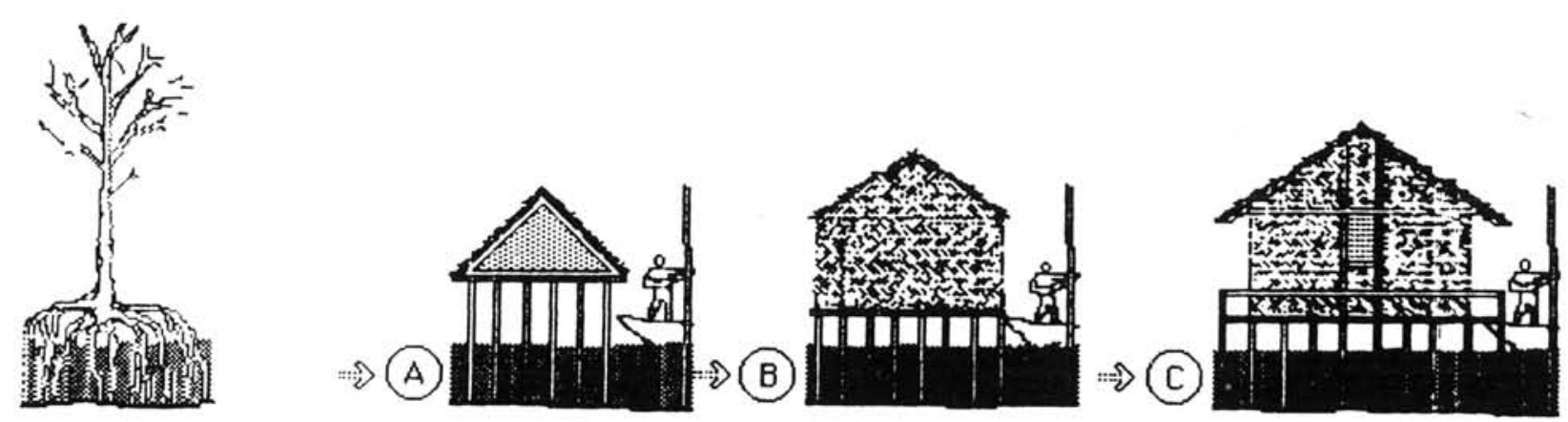

En el Zulia, a diferencia de otras latitudes, los primeros habitáculos se vinculan al agua. Respuesta acertada al sol inclemente y a la necesidad de protección nocturna ante el acoso de animales... fieras, alimañas o simplemente la plaga de mosquitos. Alli el hombre se aisló y levantó sus zancos sobre el surco de los caños, rios o lagunas, para recibir la atemperada brisa que surca por sus cauces. Alli los palafitos, que como mangles erigieron sus raíces de aéreas pretensiones. Alli los pobladores del agua, que al igual que los de tierra, han elegido su elemento como el seno de sus mitos.

A partir quizás del mangle, un arbusto lacustre común en el ecosistema zuliano, el nativo produjo por analogia su hábitat, para luego evolucionar hacia formas más complejas.

Los asentamientos palafíticos que pueblan las riberas del Lago de Maracaibo y de sus afluentes, es una arquitectura que surge de sus aguas, cuya singularidad no sólo reside en su emplazamiento o en la coherencia de su diseño con el clima, sino también por el hecho de haber perdurado como modelo desde antes de la conquista española hasta nuestros días.

En la actualidad estas poblaciones se ven urgidas de una acción preservacionista en pro de superar el desamparo total que padecen..., escuelas sin maestros, dispensarios sin médicos, iglesias sin curas..., una marginalidad que los agobia. Por otra parte también es necesario denunciar y frenar una triste politica mal llamada turística, que los condena a ser imágenes folklóricas de un pintoresco subdesarrollo; produciéndose asi un proceso acelerado de autodestrucción, a causa del trastocamiento de sus valores más profundos.

En la actualidad el paradigma del hábitat palafítico no sólo ha evolucionado, sino que también ha extendido sus dominios a diferentes puntos de la geografía del litoral lacustre de la región.

“... De suerte que paraujano, como corrupción de pararuanú, significaria en estos dialectos indiós o gentes de la orilla del mar o pescadores, como efectivamente lo son los Paraujanos".

"Los principales poblados de los Paraujanos son las trés aldeas lacustres construidas dentro de la laguna de Sinamaica, Ilamadas Boca del Caño, El Barro y Sinamaica"... "La más importante de las aldeas de la la. guna es El Barro que tiene cuatrocientos habitantes y sesenta chozas situada en la boca del río Socuy o Li. món. El censo de 1891 arroja para El Barro 71 casas y 463 habitantes y para la Boca del Caño 60 casas y 427 habitantes y para Sinamaica 300 habitantes en unas 50 casas aproximadamente".(8)

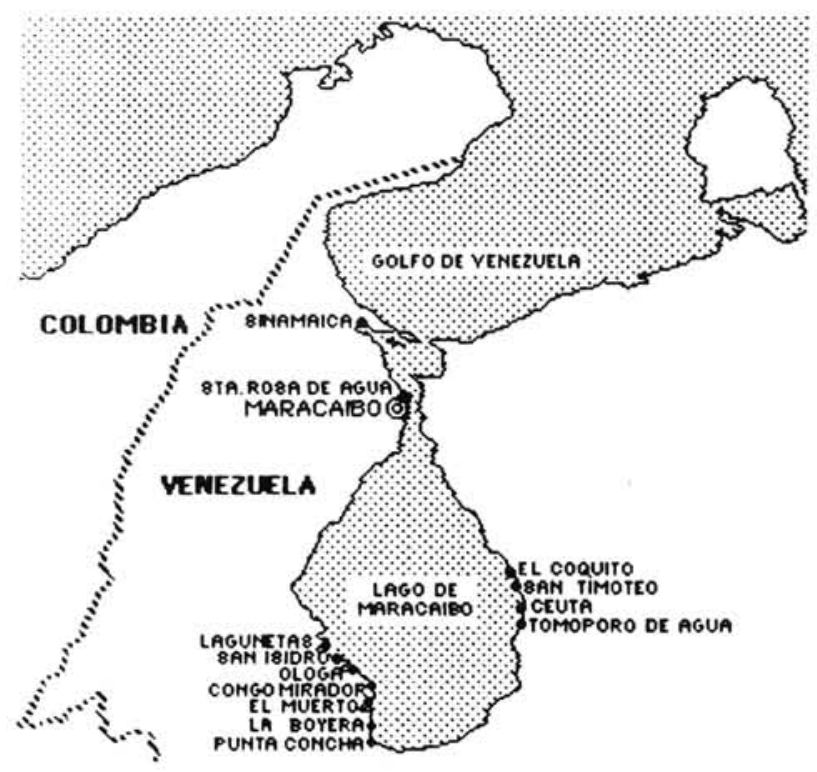

Los palafitos correspondientes al tipo - A- estaban ubicados en la desembocadura del Rio Limón (Sinamaica).

Los palafitos correspondientes al tipo - B- que aún perdura, se 10 . calizan en la misma zona que los del tipo A.

Los palafitos correspondientes al tipo - C - se hayan presentes en todos los asentamientos que hoy perviven, los cuales se señalan en el mapa anexo. 


\section{Tipologias de palafitos}

\begin{tabular}{|c|c|c|c|}
\hline \multicolumn{4}{|r|}{ ASPECTOS MORFO-FUNCIONALES } \\
\hline \multicolumn{2}{|l|}{$\begin{array}{l}\text { Villa Capra (1552-) } \\
\text { El Escorial (1559-84) } \\
\text { Ermita de Santa Ana (1607-.) } \\
\text { Conv. de S. Francisco (1618-.) } \\
\text { Palais de Versailles (1661-1756) }\end{array}$} & A. $T$ & $\begin{array}{l}\text { Un prisma triangular acostado, apoyado sobre horcones-pilotes. } \\
\text { La techumbre con armaduras de varas recubiertas con palmas } \\
\text { o eneas vinculadas por lianas o cuerdas vegetales. } \\
\text { El piso son varas amarradas al maderamen que vincula los hor- } \\
\text { cones. } \\
\text { La separación del piso con el agua es de aproximadamente } \\
1.50 \text { m. } \\
\text { El espacio es sólo para dormir y su altura sólo permite el movi- } \\
\text { miento de un hombre agazapado. } \\
\text { La función esencial es la de protección. }\end{array}$ \\
\hline Monticello (1770-78) & $\stackrel{1900}{19}$ & B. HÁBITAT CONSOLIDADO & $\begin{array}{l}\text { Un prisma pentagonal acostado. Los horcones son pasantes } \\
\text { hasta el techo, con una estructura horizontal intermedia que sos- } \\
\text { tiene el piso. } \\
\text { Techos y vanos laterales con varas donde se entretejen palmas } \\
\text { o eneas. } \\
\text { El espacio es más alto y amplio lo cual permite otros usos, de } \\
\text { alli una mayor permanencia en él. } \\
\text { Con el tiempo surgen en esta tipologia al aparecer techos con } \\
\text { cuatro aguas. En todos los casos éste se independiza de las su- } \\
\text { perficies verticales y se articula con transversales que actúan } \\
\text { como vigas de borde. } \\
\text { El hábitat llega a tener hasta tres volúmenes perfectamente di- } \\
\text { ferenciables a pesar de su proximidad. } \\
\text { Disminuye la distancia piso-agua y se consideran los vientos } \\
\text { dominantes para su orientación. } \\
\text { Coloración propia de los materiales, resaltando el valor de las } \\
\text { texturas. }\end{array}$ \\
\hline $\begin{array}{l}\text { La Casa Milá (1905-10) } \\
\text { Robie House (1908-09) } \\
\text { Ville Savoye (1928-31) } \\
\text { Colonias Petroleras } \\
\text { Falling Water (1936-37) } \\
\text { Unid. Hab. R. Urdaneta (1943) } \\
\text { Unidad Hab. Marsella (1948) } \\
\text { Famsworth House (1950) } \\
\text { Casa en Caraballeda (1958) }\end{array}$ & 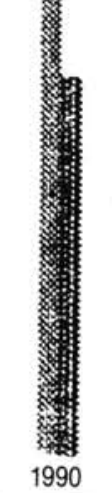 & $\begin{array}{l}\text { C. HÁBITAT AGRUPADOS } \\
\text { ASENTAMIENTOS SEMI-URBANOS }\end{array}$ & $\begin{array}{l}\text { Las unidades habitables cuentan por lo general con más de un } \\
\text { volumen y se ubican cercanas a la ribera. En ocasiones se vin- } \\
\text { culan las casas con pasarelas y se producen pequeños muelles } \\
\text { de atraque. Surgen galerias como espacios de transición entre } \\
\text { exterior-interior. Ventanas y puertas aparecen claramente defi- } \\
\text { nidas. } \\
\text { Se incorporan nuevos materiales y tecnologias: maderas trata- } \\
\text { das, perfiles metálicos, planchas de aglomerados y pilotes de } \\
\text { concreto. Se cambian por materiales compactos los vanos de } \\
\text { eneas que permitian por sus instersticios penetrar la brisa y suc- } \\
\text { cionar el aire caliente, lo cual genera una situación térmica des- } \\
\text { favorable. Aunque este cambio permitirá el uso de pinturas que } \\
\text { a partir del código cromático de Maracaibo, dará particular co- } \\
\text { lorido a alguno de estos conjuntos. }\end{array}$ \\
\hline
\end{tabular}




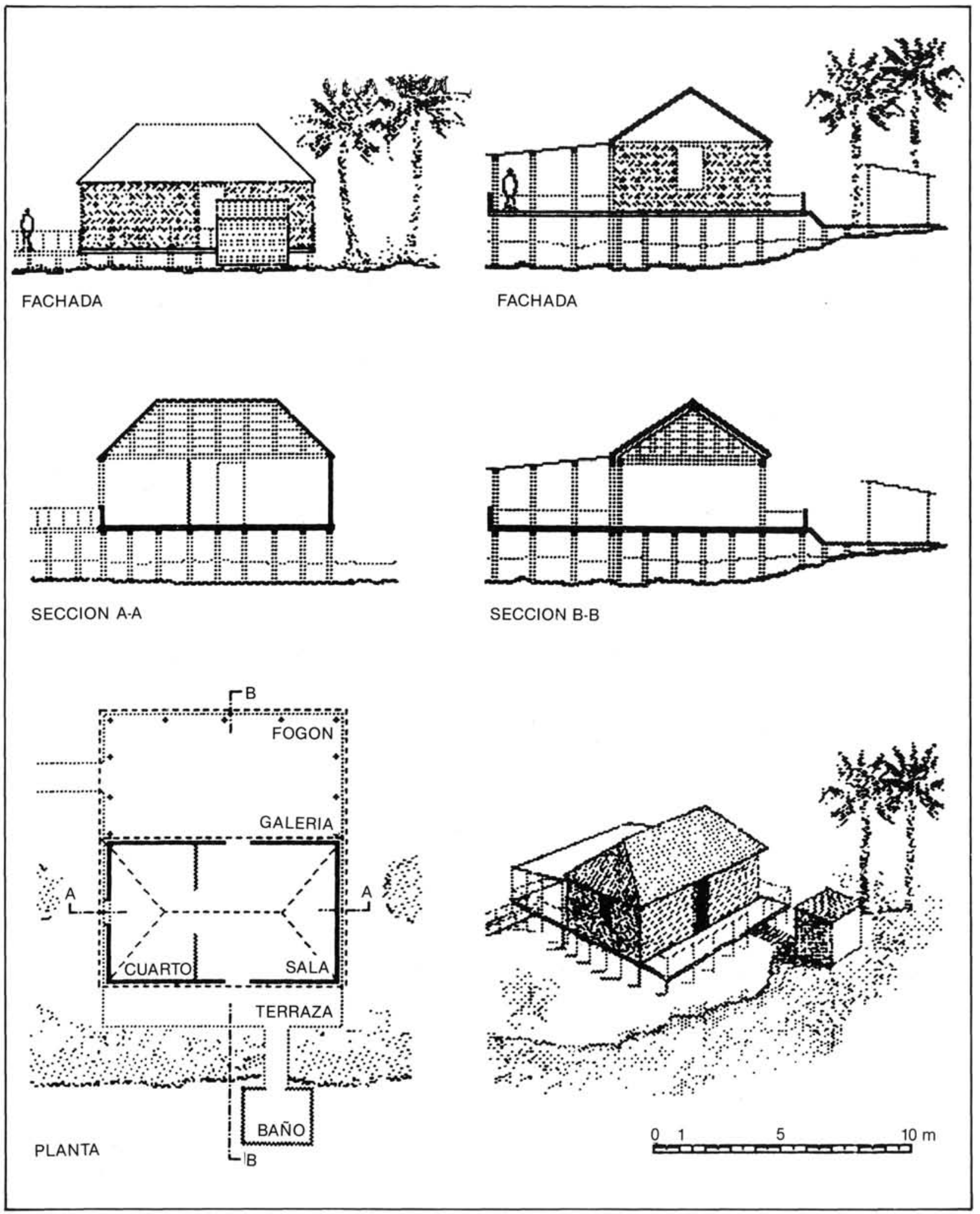




\section{COMUNION}

\section{A Frutos Vivas y Andrés García.}

"En diálogo continuo con el hombre fue creciendo el espacio en giraquitasol de esquinas y de calles. Todo transfiere al ritmo de su paso a las altas ventanas donde cuelga ese abrirse por dentro la claridad del aire, al gesto que descubre el grito del color y lo sitúa, dador de fuego,

en su recinto de habla.

Buscandose en el hueso,

elevó la cumbrera, puso el friso,

$y$ en romanillas,

juego de luz y tinajero de aire,

sembró en diseño-atmósfera la palma.

De nuevo, en esa dimensión de la memoria que enraizó el palafito con el mangle y en la rosa del tiempo se detuvo el verbo, Vos sois, señor el habitante, la medida y el molde de las cosas, ese signo vertido en el espacio, que vuelve comunión ciudad, casa y palabra y domestica al sol en el ritual desnudo del espiritu".*

- DE LA CRUZ, Ignacio. Viñetas de Maracaibo. Maracaibo. Editorial del Lago, Venezuela. 1979

\section{HACIA UN PROYECTO DE PRESERVACIÓN}

\subsection{Objetivos generales}

Rescate y valorización del total de un acervo natural y cultural resumible en:

\subsubsection{El patrimonio ecológico}

Constituido por los biosistemas estructurantes de su medio ambiente, que en la actualidad se ven gravemente agredidos por una progresiva contaminación.

\subsubsection{El patrimonio ético-social}

Definido por las tradiciones, costumbres, modos de vida y demás condiciones determinantes de una conducta social que caracterizan antropológicamente a una región, esencias a proteger de las mistificaciones de un falso progreso, del descrédito de los valores populares y de las transposiciones culturales.
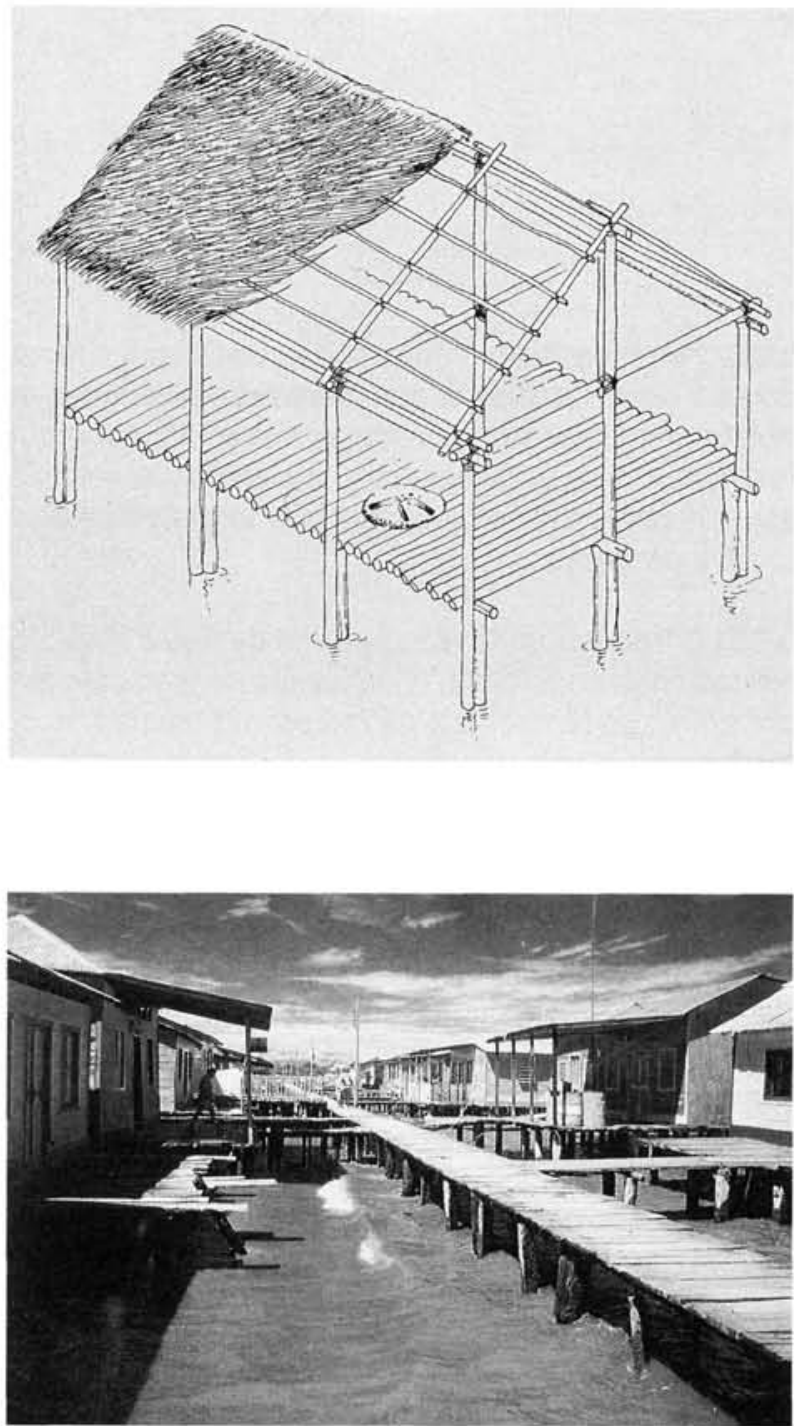

\subsubsection{El patrimonio arquitectónico}

Conformado por espacios públicos y privados cuyas caracteristicas individuales o de conjunto son indicativos de un oficio arquitectónico de ponderables res. puestas a sus requerimientos funcionales, formales y en nexo con el contexto donde emergen.

\subsection{Objetivos especificos}

5.2.1. Preservar una arquitectura popular claro ejemplo de la idoneidad natural de la comunidad para resolver su hábitat, sin duda paradigma insoslayable para las acciones de diseño de este medio. 
5.2.2. Poner en "valor" una praxis que integra a moradores y constructores al plasmarse sus relaciones en objetos dinámicos de constante mutación, dado que las mediaciones primarias hombre-materia y necesidadespacio generan una dialéctica que totaliza a productores y producto.

5.2.3. Conservar un legado cultural de riquísimas significaciones, concretado en espacios de gran coherencia expresivo-funcional y de radical simbiosis con su medio.

\subsection{Criterios de acción}

La acción preservacionista no sólo se orientará a mantener y/o acondicionar los actuales asentamientos palafíticos, sino también y de manera muy especial establecer los medios tendentes al rescate de sus principios morfo-estéticos y la ponderación de sus formas de vida, con el objeto de desentreñar sus códigos arquitectónicos como base de un proyecto comunitario que integre a diseñadores y usuarios.

En tal sentido la propuesta preservacionista planteará dos situaciones de diseño con objetivos comunes, pero con estrategias disímiles. La primera destinada a la conservación y consolidación de los actuales asentamientos, la segunda inductora de nuevos proyectos a partir de un método analógico.

\subsection{Estrategias}

\subsubsection{Estrategia-A-. Preservación de los presentes núcleos.}

Si bien la magnitud de los asentamientos palafíticos no superan la designación de centros semi-urbanos, será inevitable a la luz de una propuesta preservacionista considerar niveles dimensionales más extensos que den cuenta del contexto lacustre que le es común.

La íntima relación palafito-lago impide un tratamiento unilateral de los espacios construidos, soslayando los problemas de un medio seriamente afectado por un acelerado proceso de contaminación. Derrames petroleros, desagotes cloacales incontrolados, vertientes de desechos industriales y todo tipo de botaderos de basuras, son los principales gestores de una depredación ambiental que puede ver a corto plazo extinguida toda la vida que generó.
De lo expuesto podemos inferir que un proyecto preservacionista para estos núcleos deberá estructurar. se y articularse en función de un conjunto de escalas que acoten las áreas de acción de la propuesta; las cuales a continuación se detallan:

\section{A. - Escala regional}

Diseño a nivel de CONSERVACION AMBIENTAL, que deberá surgir de un equipo interdisciplinar, en condiciones de abordar tanto las acciones de descontaminación como de prevención.

\section{B. - Escala semi-urbana}

Diseño a nivel de REHABILITACION, que deberá rescatar estos núcleos de su actual marginalidad en función, no sólo de dotarlo de servicios generales y actualizar sus espacios de acuerdo a nuevas necesidades, sino también de revitalizar su proceso económico-social.

\section{C. - Escala de recintos}

Diseño a nivel de RESTAURACION, destinado a la reconstrucción y acondicionamiento de espacios deteriorados o sin los servicios básicos para un mínimo confort. Dadas las características de estos erites arquitectónicos dispersos en el medio lacustre, considero es de descartar cualquier modo tradicional de instalación de estos servicios y plantear otras soluciones como los sistemas individuales de generación de energia, tratamiento de aguas y reciclaje de residuos.

\subsubsection{Estrategia (B) preservación de criterios en el di- seño palafítico}

La tesis a desarrollar en esta segunda estrategia se basa en el método de diseño denominado analógico ("... la analogía es el mecanismo central de la creatividad y todos los arquitectos que llamamos creativos 10 han usado en un momento u otro de sus carreras'.'(9). Tesis que bien pudiera enunciarse a partir de los trabajos elaborados por Geoffrey Broadbent, Aldo Rossi y algunos otros estudiosos de estos aspectos del diseño.

Para explicitar más este marco referencial, diré que de. bemos considerar lo análogo en el sentido de semejanza, relación, transferencia en ciertos procesos; que para el caso de la arquitectura implica sin duda una transposición selectiva de propiedades de una situación a otra, de unos espacios a otros, conllevando una articulación histórica fundamental en el desarrollo de los centros urbanos. 
Estos conceptos extrapolados al restricto campo que nos ocupa constituirian un marco teórico vertebral, inductor de una praxis proyectual comprometida tanto con una preservación de estilos de vida y como de morfologias de múltiples significaciones.

Aldo Rossi al referirse a este problema planteará lo siguiente: "Con la hipótesis de la ciudad análoga, entiendo referirme a las cuestiones teóricas del proyectar en arquitectura, esto es, a un procedimiento compositivo que gira sobre algunos hechos fundamentales de la realidad urbana y en torno a los cuales construye otros hechos en el marco de un sistema analógico(...). Una operación lógico-formal puede traducirse en un modo de proyectar(...); de una teoria del proyectar arquitectónico donde los elementos están prefijados, formalmente definidos, pero donde el significado que nace al término de la operación es el sentido auténtico, imprevisto, original de la investigación"'(10)

"Creo en una arquitectura que parta de la realidad, que ela. bore una interpretación crítica de ella, y que vuelva a la realidad, modificándola con dialéctica incesante"**

- VILLANUEVA, Carlos Raúl. Textos escogidos. Editado por el CID de la Facultad de Arquitectura y Urbanismo de la U.C.V. Caracas, 1980

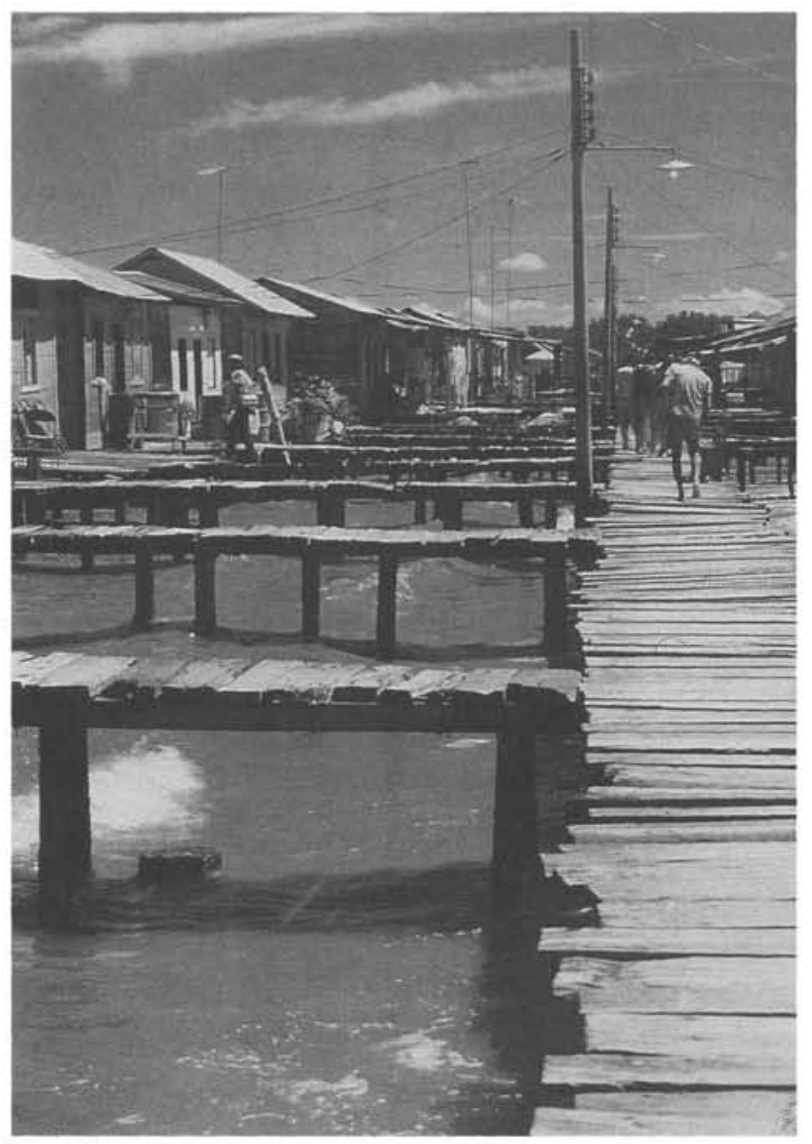

\section{BIBLIOGRAFIA}

(1) ALBERTI, Leon Battista. De re aedificatoria. Madrid, 1582. (Facsimil) Albastro Ed., Valencia 1977.

(2) GARCIA I., Andrés. Colloque d'“Esthétique appliquée à la création du paysage urbain". Paris, Ed. CEE, p. 223, 1975.

(3) FERNANDEZ ALBA, Antonio. "La arquitectura de los márgenes". Sumarios 38. p. 43. Buenos Aires, 1979.

(4) VILLANUEVA, Carlos Raúl. Textos escogidos. Editado por el CID de la Facultad de Arquitectura y Ur. banismo de la U.C.V. Caracas, 1980.

(5) PERRAULT, C. (Trad. de J. Castañeda). Compendio de los diez libros de arquitectura de Vitruvio. Murcia. Ed. Galería Librería Yerba. España, 1981.
(6) CARAMUEL DE LOBKOWITZ, Juan. Architectura civil Recta y Oblicua considerada y dibuxada en el templo de Jerusalén. Vigevano, 1678. Madrid, Turner Ed. (facsimil), 1984.

(7) JAHN, Alfredo. Los aborigenes del occidente de Venezuela. Caracas. Monte Avila Ed., p. 206, 1973.

(8) JAHN, Alfredo. Los aborigenes del occidente de Venezuela. Caracas. Monte Ávila. Ed., 1973.

(9) BROADBENT, Geoffrey. Diseño arquitectónico. Ed. Gustavo Gili. Barcelona, 1976. Pág. 397.

(10) ROSSI, Aldo. Textos de Aldo Rossi. Revista Sumarios 22. p. 140. Edic. Summa. Buenos Aires, 1979. 